\title{
The Electric Variable Transmission
}

\author{
Martin J. Hoeijmakers, Member, IEEE, and Jan A. Ferreira, Fellow, IEEE
}

\begin{abstract}
First, an electromechanical converter with two mechanical ports and one electrical port (consisting of two concentric machines and two inverters) is considered. This converter works as a continuously variable transmission between the mechanical ports and may, e.g., replace the clutch, gearbox, generator, and starter motor in a motor vehicle. The working principle of this converter is explained. Next, a new converter, the electric variable transmission (EVT), is presented. This converter has similar properties, but is smaller and lighter. The EVT may be seen as built up from two concentric induction machines with a combined relatively thin yoke. Thus, we obtain one electromagnetic device instead of two magnetically separated devices. The working principle of the EVT is explained, and its losses are discussed.
\end{abstract}

Index Terms-AC machines, automotive, electromechanical converter, electromechanical transmission, hybrid electric vehicle, vehicle power systems, vehicle propulsion.

\section{INTRODUCTION}

$\mathbf{I}$ $\mathrm{N}$ THIS paper, a description is given of the electric variable transmission (EVT), which may replace the clutch, gearbox, starter, and generator in buses and light trucks. We can regard the set clutch, gearbox, starter, and generator as an electromechanical converter (Fig. 1) with two mechanical ports (to the engine and to the differential) and one electrical port (to the battery).

One of the disadvantages of the electrical part of the conventional system is the wear of the starter. This limits the number of starter actions and is an important reason for city buses not to switch off their engines at bus stops (which would be more comfortable and reduce the fuel consumption). Another disadvantage is the belt-driven generator, which has a low efficiency and a low maximum power rating. These disadvantages are the reason for a big R\&D interest in starter-generators (see, e.g., [1]-[3] or [4]).

Furthermore, a conventional gearbox has a limited number of gear ratios, which is not optimal for the combustion engine. A continuously variable transmission allows the engine to work with better efficiency, which can result in a considerable reduction of the fuel consumption, especially if the overdrive region is large (see [5]).

A proper electromechanic system can overcome the disadvantages of the conventional system mentioned above. Here, we will develop such an electromechanic system, resulting in

Paper IPCSD-06-033, presented at the 2004 Industry Applications Society Annual Meeting, Seattle, WA, October 3-7, and approved for publication in the IEEE TRANSACTIONS ON INDUSTRY APPLICATIONS by the Industrial Drives Committee of the IEEE Industry Applications Society. Manuscript submitted for review October 15, 2004 and released for publication April 26, 2006.

The authors are with the Electrical Power Processing Unit, Delft University of Technology, 2628 CD Delft, The Netherlands (e-mail: m.j.hoeijmakers@ tudelft.nl; J.A.Ferreira@EWI.TUDelft.NL).

Digital Object Identifier 10.1109/TIA.2006.877736

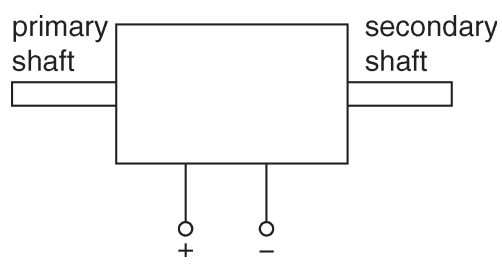

Fig. 1. Considered system.

the EVT, which is an electromechanic converter with two rotors and a stator.

Before doing so, we will shortly look at the possibility to use the electrical port to connect an energy storage unit, which is larger than a normal battery. Thus, we get a hybrid drive system: The mechanical energy for the differential may be supplied by the engine as well as by the electrical source.

There are many kinds of hybrid systems of which the series and parallel hybrids are well known. The EVT may be seen as a series-parallel hybrid or split-power hybrid system (see, e.g., [6]-[9] or [10]).

In a split-power hybrid system, the power from the combustion engine is split up into a part (nearly) directly sent to the wheels and a part sent through power electronic converters. The Toyota Prius is a well-known example of such a system. In this case, a planetary gear is used for the power split [11], [12]. However, it is also possible to realize a split-power hybrid system by means of the combination of two electric machines, which may be arranged concentrically, without a mechanical gear [13]. Section II is an introduction to the realization of a split-power hybrid system with two concentrically arranged machines. Here, and in the remainder of this paper, we will have a look at a system for the case that it is used as a continuously variable transmission (no electric energy storage). The basic idea for the concentrically arranged machines is already very old (1935, using dc machines [14]). More recent implementations (like [15]-[17]) are discussed at the end of Section II.

In Sections III and IV, we will introduce the EVT as a special case and look at a simple model. This model is used to discuss some characteristic operation modes and the losses in the system. Finally, we will pay some attention to the proof of concept.

\section{SYSTEM CONCEPT}

\section{A. Cascade System}

A better electromechanic system for a vehicle might be a cascade system of a dc generator (ac generator with rectifier) and a dc motor (inverter with ac motor), as shown in Fig. 2. In this case, we use an unconventional generator in which the squirrel-cage winding is on the stator, and the electric power is 


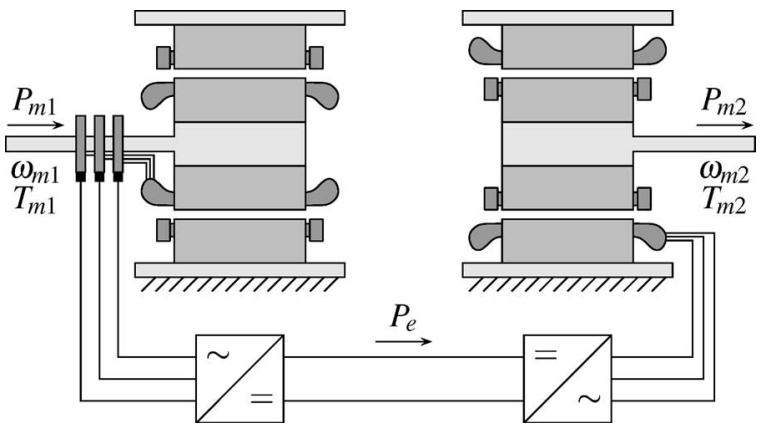

Fig. 2. Cascade system.

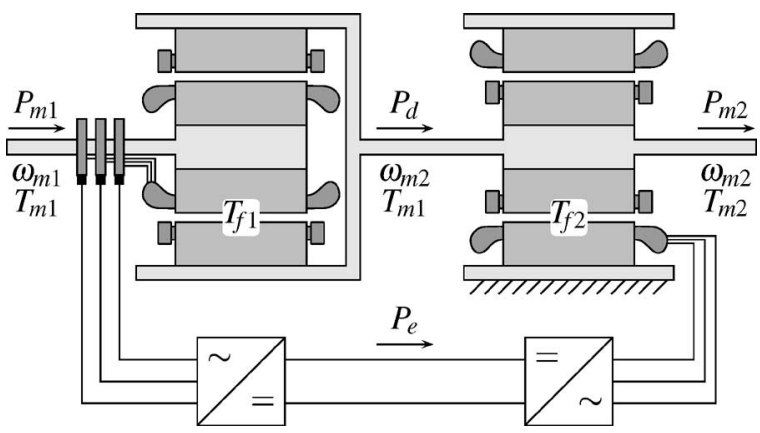

Fig. 3. Basic idea.

withdrawn from the rotor (the rotor of a wound-rotor induction machine with sliprings). This choice is made for the further development of the system.

As mentioned before, we will have a look at this system for the case where it is used as a continuously variable transmission (without a battery on the dc link). For the explanation, the system is assumed to be lossless (also no losses in the squirrelcage windings).

The system is supplied by the primary shaft power, i.e.,

$$
P_{m 1}=\omega_{m 1} T_{m 1}
$$

where $\omega_{m 1}$ is the rotational speed, and $T_{m 1}$ is the (mechanical) torque. This power is converted into the electrical power $P_{e}$, which is converted to the secondary shaft power $P_{m 2}=$ $\omega_{m 2} T_{m 2}$. In this case, the full power flow is through four converters, resulting in a relatively low efficiency in reality.

This efficiency can be increased significantly if we directly lead the stator torque of the primary machine to the rotor of the secondary machine, as is shown in Fig. 3.

In this case, the electrical power generated by the primary machine is

$$
P_{e}=\left(\omega_{m 1}-\omega_{m 2}\right) T_{f 1}=\left(\omega_{m 1}-\omega_{m 2}\right) T_{m 1}
$$

where $T_{f 1}$ is the electromagnetic (field) torque, which equals $T_{m 1}$.

The electric power is one part of the power flow. The other part is directly passed to the secondary shaft via the electromagnetic torque in the primary air gap, i.e.,

$$
P_{d}=\omega_{m 2} T_{f 1}=\omega_{m 2} T_{m 1} .
$$
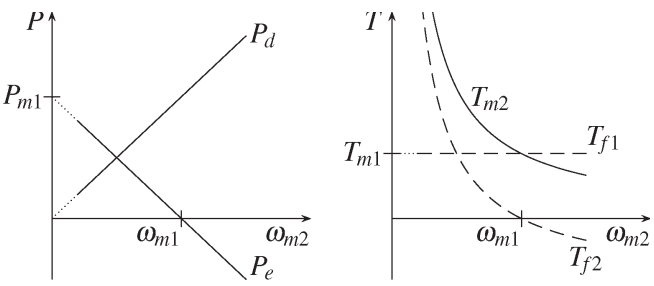

Fig. 4. Power and torque characteristics.

Thus, the power balance of the primary machine is

$$
P_{m 1}=P_{e}+P_{d}
$$

The power $P_{e}$ still is the power flow through the power electronic converters with relatively high losses (in reality). The power $P_{d}$ is the power flow directly passed from the primary rotor to the secondary rotor with relatively low losses. The powers $P_{d}$ and $P_{e}$ as a function of the secondary rotational speed $\omega_{m 2}$ are shown in the left graph of Fig. 4. The parts of the graphs for low values of $\omega_{m 2}$ are dotted because the assumption that the system is lossless is not reasonable in this region.

The secondary shaft torque $T_{m 2}$ consists of the contribution of the primary air-gap (field) torque $T_{f 1}=T_{m 1}$ and the secondary air-gap torque, i.e.,

$$
T_{f 2}=\frac{P_{e}}{\omega_{m 2}}=\frac{\omega_{m 1}-\omega_{m 2}}{\omega_{m 2}} T_{m 1}
$$

where we used the power balance of the stator of the secondary machine and (2).

Thus, we found the following for the secondary shaft torque (as expected):

$$
T_{m 2}=T_{f 1}+T_{f 2}=\frac{\omega_{m 1}}{\omega_{m 2}} T_{m 1} .
$$

The torques as functions of the secondary rotational speed are shown in the right graph of Fig. 4.

As we can see in Fig. $4, P_{e}$ is relatively small in the region around $\omega_{m 2}=\omega_{m 1}$ (direct drive). Thus, the losses are also relatively low in this region, and it should be the favorite operation region. For low values of $\omega_{m 2}, P_{e}$ is relatively high. In traction drive systems, this region corresponds with the acceleration, which normally does not take a long time. Thus, a good choice of the direct-drive speed can result in a relatively high efficiency for the application in traction drive systems.

\section{B. System Rating}

As we have seen, the first advantage of the cascade system of Fig. 3 above the cascade system of Fig. 2 is its efficiency. In this section, we will see that the second advantage is that the rating of the system components is lower.

Because a high secondary shaft torque $T_{m 2}$ (at a low secondary speed $\omega_{m 2}$ is mostly only necessary during a very short time, the continuous available (rated) torque $T_{m 2 \text {,rat }}$ can be much lower than the peak torque. Here, we use

$$
T_{m 2, \mathrm{rat}}=n_{\mathrm{rat}} T_{m 1, \mathrm{rat}}
$$


(a)

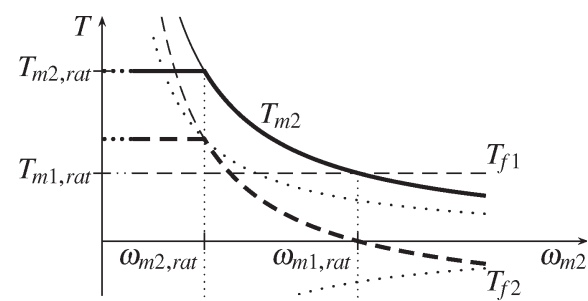

(b)

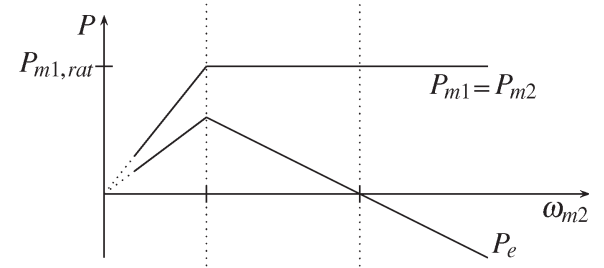

(c)

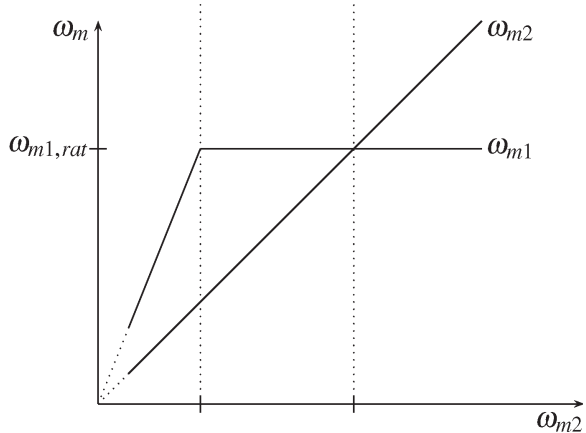

Fig. 5. System rating.

where $n_{\text {rat }}$ is the rated gear ratio. For example, in a city bus, $n_{\text {rat }}$ is probably somewhere between 2 and 2.5 , whereas the peak gear ratio can be around 5 .

For further explanation, we will use Fig. 5, and we assume that the primary shaft torque equals its rated value $T_{m 1 \text {,rat. }}$. For low values of $\omega_{m 2}$ (and $\omega_{m 1}$ ), this is not possible in the case of a combustion engine. For that reason, the curves are dotted in that region.

The secondary shaft torque for rated primary shaft torque is the bold curve in Fig. 5(a), which is derived from the right side of Fig. 4. Because there are no losses, the rated secondary shaft speed follows from

$$
\omega_{m 2, \mathrm{rat}}=\frac{1}{n_{\mathrm{rat}}} \omega_{m 1, \mathrm{rat}}
$$

The region on the right side of $\omega_{m 2 \text {,rat }}$ is the constant-power region [see Fig. 5(b)]. Because $T_{m 1}$ is assumed to be constant $\left(T_{m 1, \text { rat }}\right)$, the primary speed is also constant in this region [Fig. 5(c)]. In the region on the left side of $\omega_{m 2}$,rat, the secondary torque is constant. Thus, the power [Fig. 5(b)] and the primary speed [Fig. 5(c)] are proportional to the secondary speed here.

For the rating of the primary machine, we look at Fig. 5(c) and remind that the primary torque equals $T_{m 1 \text {,rat }}$. When we neglect the magnetizing current and assume the flux to be constant, this torque corresponds with the current. With a constant flux, the voltage corresponds with the rotational speed seen by the primary machine $\left|\omega_{m 1}-\omega_{m 2}\right|$. The maximum of this difference occurs at $\omega_{m 2}=\omega_{m 2 \text {,rat }}$. Thus, the rated electrical power for the primary machine is [using (8)]

$$
\begin{aligned}
P_{e 1, \mathrm{rat}} & =T_{m 1, \mathrm{rat}}\left(\omega_{m 1, \mathrm{rat}}-\omega_{m 2, \mathrm{rat}}\right) \\
& =T_{m 1, \mathrm{rat}} \omega_{m 1, \mathrm{rat}} \frac{n_{\mathrm{rat}}-1}{n_{\mathrm{rat}}} .
\end{aligned}
$$

When we look at Fig. 5(c), we can see that $\left|\omega_{m 1}-\omega_{m 2}\right|$ also becomes larger for relatively large values of $\omega_{m 2}$. We do not consider that case here.

For the rating of the secondary machine, we look at Fig. 5(a). For $\omega_{m 2}<\omega_{m 2, \text { rat }}$, the torque contribution of the secondary air gap $T_{f 2}$ is maximum, i.e., $\left(n_{\text {rat }}-1\right) T_{m 1 \text {,rat }}$. In that region, the maximum power occurs at $\omega_{m 2}=\omega_{m 2 \text {,rat }}$. Thus, the maximum power in that region is again $T_{m 1, \text { rat }} \omega_{m 1, \text { rat }}\left(n_{\text {rat }}-1\right) / n_{\text {rat }}$ [see (9)]. For $\omega_{m 2}>\omega_{m 2 \text {,rat }}$, we can use field weakening in the secondary machine, so that the flux is inversely proportional to the rotational speed. In that case, the voltage is constant. If the current is kept at a constant value, the torque is a hyperbolic function of the rotational speed. These are the dotted curves in Fig. 5(a). As we may see, $T_{f 2}$ is always between those curves except for the case of higher values of $\omega_{m 2}$, which we do not consider here. Thus, the maximum again occurs at $\omega_{m 2}=$ $\omega_{m 2 \text {,rat }}$, and we may also use (9) for the secondary machine.

Because we considered the currents and the voltages of both machines, expression (9) for the power rating is also valid for the power electronic converters. Furthermore, we can find the value from expression (9) in the maximum of $P_{e}$ in Fig. 5(b).

In the foregoing, we did not consider a possible magnetizing current. An extra magnetizing current component (in an induction machine) results in a higher (apparent) power rating. When we consider the example of a city bus from [5], we find an apparent power rating for the (induction) machines and the power electronic converters of about $65 \%$ of the rated power of the combustion engine.

\section{Practical Implementation}

For the practical implementation of a continuously variable transmission, the secondary machine is concentrically arranged around the primary machine, as shown in Fig. 6.

We will again have a look at this system for the case that it is used as a continuously variable transmission. However, we will take the most important losses into account. Furthermore, we replace primary by inner (the subscript 1 by $i$ ) and secondary by outer (the subscript 2 by $o$ ) on some places.

The system is supplied by the primary shaft power $P_{m 1}=$ $\omega_{m 1} T_{m 1}$ (see Fig. 7). This power is split up into two parts. The part

$$
P_{f i}=\omega_{f i} T_{m 1}
$$

( $\omega_{f i}$ is the rotational speed of the field in the inner air gap) is directly passed to the secondary shaft via the inner squirrel-cage winding $\left(T_{m 1}=T_{f i}=T_{m c i}\right)$. However, we have the losses $P_{c i}$ in the inner squirrel-cage winding, i.e.,

$$
P_{m c i}=P_{f i}-P_{c i}=\left(\omega_{f i}-\frac{\omega_{\text {slip }, i}}{p}\right) T_{m 1}
$$




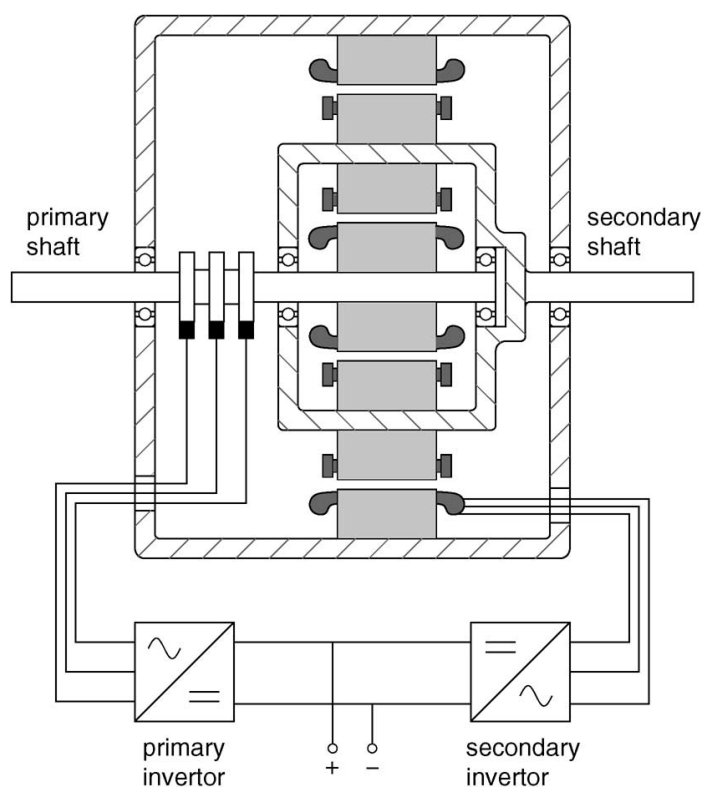

Fig. 6. Two concentric induction machines.

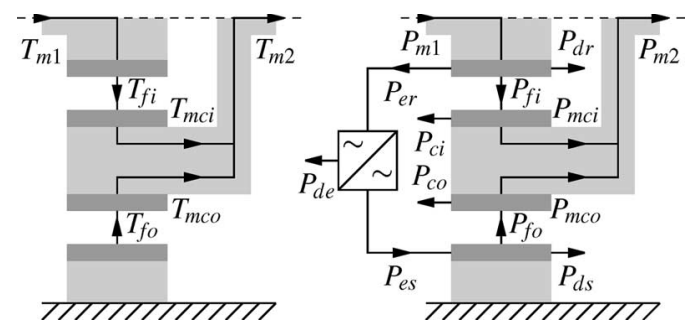

Fig. 7. Torque and power reference directions for two concentric induction machines.

where we used

$$
\omega_{\text {slip }, i}=p\left(\omega_{f i}-\omega_{m 2}\right)
$$

which is the slip angular frequency and where $p$ is the number of pole pairs.

In the other power flow, we have the rotor (copper and iron) losses $P_{d r}$. Thus, the electrical power obtained from the rotor (sliprings) is

$$
P_{e r}=\left(\omega_{m 1}-\omega_{f i}\right) T_{m 1}-P_{d r}
$$

This power is supplied to the power electronic converters with the losses $P_{d e}$. Thus, the electric power supplied to the stator is

$$
P_{e s}=P_{e r}-P_{d e}
$$

After subtraction of the stator losses $P_{d s}$ (copper and iron), we get the air-gap (field) power, which is directly related to the airgap torque, i.e.,

$$
P_{f o}=P_{e s}-P_{d s}=\omega_{f o} T_{f o} .
$$

As in a normal squirrel-cage induction machine, this power is converted into the mechanical power $P_{m c o}$ with the loss in the outer squirrel-cage winding $P_{c o}$. This corresponds with the contribution $T_{m c o}=T_{f o}$ to the secondary shaft torque $T_{m 2}$.
Because a system with two concentric machines is a continuously variable transmission, it allows a better use of the engine in a vehicle, in which it also works as a starter motor and a generator (with a high efficiency). Of course, the idea can also be applied in other application than vehicles, e.g., dredgers or the combinations of an expander and a compressor, which exchange mechanical energy with supply or withdraw of electrical energy.

The idea of two concentric machines has been implemented in various ways. As mentioned before, a patent of 1935 already mentions a combination of two dc machines [14]. In a later patent, a machine set with one or more diode/thyristor converters is described [15]. Nowadays, combinations of permanentmagnet machines or induction machines are obvious.

The combination of two permanent-magnet machines is described in, e.g., [17] for the use of the system in a hybrid vehicle. Compared to induction machines, permanent-magnet machines have the advantages of high torque density and missing slip losses. However, it is difficult to weaken the field, which is especially important for the outer machine at high vehicle speeds. Furthermore, the iron losses in the outer machine can be considerable [18].

A special implementation example is given in [16]. Here, the secondary rotor is very thin and only contains one squirrelcage winding. As a result, the inner air-gap flux always (nearly) equals the outer air-gap flux. This means that it is impossible to weaken the flux in the outer machine without weakening the flux in the inner machine, which is desired when driving at a high speed and a high input torque. The result is that the iron losses are high when driving at a high speed and that a large secondary inverter is necessary.

A big disadvantage of the machine in Fig. 6, consisting of two induction machines, is its size and its weight. In this paper, a new electromechanic conversion system with similar properties is presented, which is much smaller and lighter.

\section{EVT}

If the inner and outer machines have the same slip frequency (including the direction), the fields of both machines rotate with the same speed, and we can strongly reduce the height of the yokes attached to the rotor of the secondary shaft. In this way, we get the machine in Fig. 8. This system is named the EVT.

The rotor on the secondary shaft is named the interrotor: It rotates between the (primary) rotor and the stator. The interrotor shown in Fig. 8 is just one of the possible arrangements.

The electromagnetic behavior of the EVT is totally different from two separate induction machines.

When the magnetic reluctance of the interrotor yoke is very small, the EVT works as two concentric induction machines. However, the interrotor yoke height is much smaller than the rotor yoke or the stator yoke height. As a result, the interrotor yoke is saturated, and the inner and outer machines are not magnetically separated anymore. In fact, we now get one electromagnetic device instead of two, in which there is also a direct interaction between the (slipring armature) rotor and the stator.

An easy way to see this direct interaction is to consider the case that there is no stator current and that the slip frequency 


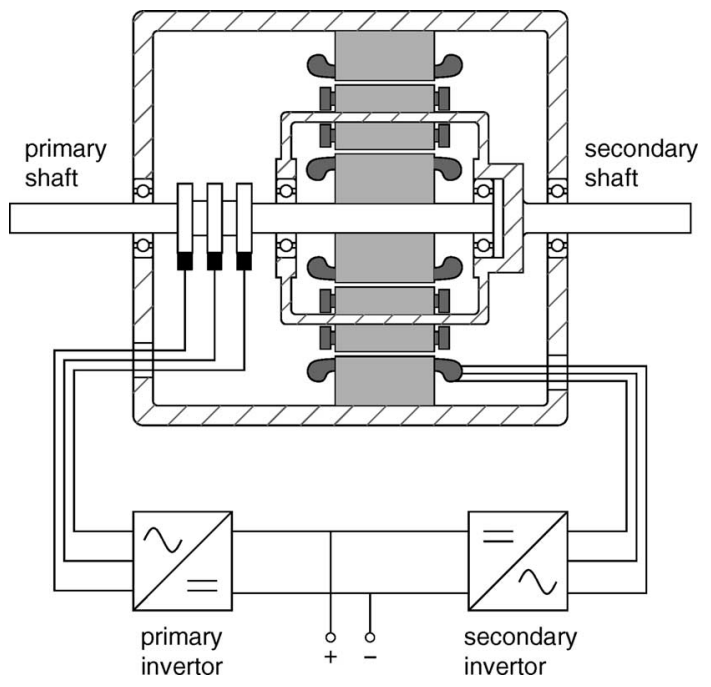

Fig. 8. EVT.

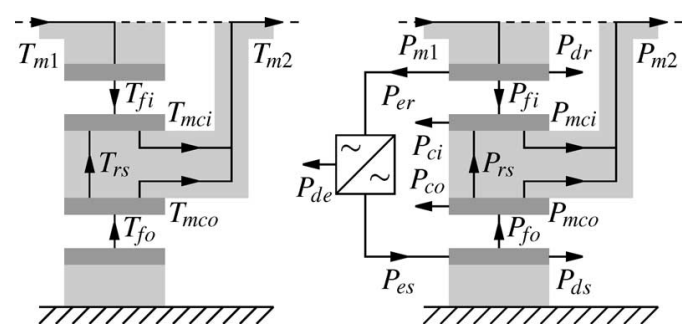

Fig. 9. Torque and power reference directions for the EVT.

seen by the squirrel-cage windings is zero (thus, there is also no current in the squirrel-cage windings). We increase the rotor current from zero. First, the rotor flux will pass the interrotor yoke tangentially. When the interrotor yoke saturates, a part of the rotor flux will cross the outer air gap and pass the stator yoke. When we next apply a stator current vector, which has another direction than the rotor current vector, we get a direct torque between the stator and the rotor. This torque, which is not in the system with two concentric induction machines (Fig. 7), is named $T_{r s}$ (see Fig. 9). This torque leads to a kind of synchronous-machine behavior between the rotor and the stator through the interrotor. Thus, the air-gap torque of the inner machine consists of two components, i.e.,

$$
T_{f i}=T_{m c i}-T_{r s} .
$$

The field plots given in [5] may give a better insight in the interrotor yoke saturation.

\section{Simple Model of the EVT}

Because there is still no good validated EVT model available, especially not for the interrotor yoke saturation, we will derive a simple model based on well-known expressions for the induction machine. Later, we will only use this model to get an idea of the system losses.

First, we pay attention to angular frequencies and angular speeds. In the EVT, the angular speed of the field in the inner and outer parts are the same (i.e., $\omega_{f i}=\omega_{f o}=\omega_{f}$ ). Thus, the slip frequencies in both squirrel-cage windings are also equal (i.e., $\omega_{\text {slip }, i}=\omega_{\text {slip }, o}=\omega_{\text {slip }}$ ), and the relations with the stator and the rotor angular frequency are

$$
\begin{aligned}
& \omega_{s}=p \omega_{f}=p \omega_{m 2}+\omega_{\text {slip }} \\
& \omega_{r}=p\left(\omega_{f}-\omega_{m 1}\right)=p\left(\omega_{m 2}-\omega_{m 1}\right)+\omega_{\text {slip }}
\end{aligned}
$$

The torque corresponding with a squirrel-cage winding is supposed to be proportional to the slip frequency and the square of the flux linkage. Thus, we can write the torque contributions of the squirrel-cage windings as

$$
\begin{aligned}
T_{m c i} & =\frac{\omega_{\text {slip }}}{\omega_{\text {slip }, i, \mathrm{rat}}} \lambda_{i}^{\prime 2} T_{i, \mathrm{rat}} \\
T_{m c o} & =\frac{\omega_{\text {slip }}}{\omega_{\text {slip }, o, \text { rat }}} \lambda_{o}^{\prime 2} T_{o, \text { rat }}
\end{aligned}
$$

where $\omega_{\text {slip }, i, \text { rat }}$ and $\omega_{\text {slip }, o \text {,rat }}$ are the rated values of the slip angular frequencies, and $\lambda_{i}^{\prime}$ and $\lambda_{o}^{\prime}$ are the relative (per unit) values of the flux linkages (corresponding with the field weakening), i.e.,

$$
\begin{aligned}
& \lambda_{i}^{\prime}=\frac{\lambda_{i}}{\lambda_{i, \mathrm{rat}}} \\
& \lambda_{o}^{\prime}=\frac{\lambda_{o}}{\lambda_{o, \mathrm{rat}}} .
\end{aligned}
$$

The power dissipated in the squirrel-cage windings is

$$
\begin{gathered}
P_{c i}=\frac{\omega_{\text {slip }}}{p} T_{m c i} \\
P_{c o}=\frac{\omega_{\text {slip }}}{p} T_{m c o} .
\end{gathered}
$$

In the rated point, this is [using (18)]

$$
\begin{aligned}
P_{c i, \mathrm{rat}} & =\frac{\omega_{\mathrm{slip}, i, \mathrm{rat}}}{p} T_{i, \mathrm{rat}} \\
P_{c o, \mathrm{rat}} & =\frac{\omega_{\mathrm{slip}, o, \mathrm{rat}}}{p} T_{o, \mathrm{rat}} .
\end{aligned}
$$

We can easily give reasonable estimations for these rated values in the case of induction machines. If we assume that the rated torque values are known, we can use these equations to find the rated values of $\omega_{\text {slip }}$. Furthermore, we neglect the iron losses in the interrotor.

The losses in the rotor and the stator consist of the iron and the copper losses, i.e.,

$$
\begin{aligned}
& P_{d r}=P_{\mathrm{Fe}, r}+P_{\mathrm{Cu}, r} \\
& P_{d s}=P_{\mathrm{Fe}, s}+P_{\mathrm{Cu}, s} .
\end{aligned}
$$

The iron losses are supposed to be proportional to the square of the flux density and the square of the frequency, i.e.,

$$
\begin{aligned}
& P_{\mathrm{Fe}, r}=\frac{\omega_{r}^{2}}{\omega_{r, \mathrm{rat}}^{2}} \lambda_{i}^{\prime^{2}} P_{\mathrm{Fe}, r, \mathrm{rat}} \\
& P_{\mathrm{Fe}, s}=\frac{\omega_{s}^{2}}{\omega_{s, \mathrm{rat}}^{2}} \lambda_{o}^{\prime^{2}} P_{\mathrm{Fe}, s, \mathrm{rat} .} .
\end{aligned}
$$




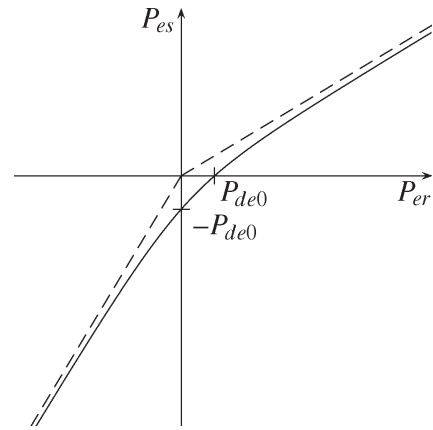

Fig. 10. Power $P_{e s}$ as a function of the power $P_{e r}$.

The copper losses are split up in a part corresponding with the air-gap torque (subscript $T$ ), i.e.,

$$
\begin{aligned}
& P_{\mathrm{Cu}, T, r}=\frac{T_{f i}^{2}}{T_{i, \mathrm{rat}}^{2}} \frac{P_{\mathrm{Cu}, T, r, \mathrm{rat}}}{\lambda_{o}^{\prime 2}} \\
& P_{\mathrm{Cu}, T, s}=\frac{T_{f o}^{2}}{T_{o, \text { rat }}^{2}} \frac{P_{\mathrm{Cu}, T, s, \mathrm{rat}}}{\lambda_{o}^{\prime 2}}
\end{aligned}
$$

and a part corresponding with the magnetizing current (subscript $\lambda$ ), i.e.,

$$
\begin{aligned}
& P_{\mathrm{Cu}, \lambda, r}=\lambda_{i}^{\prime 2} P_{\mathrm{Cu}, \lambda, r, \text { rat }} \\
& P_{\mathrm{Cu}, \lambda, s}=\lambda_{o}^{\prime 2} P_{\mathrm{Cu}, \lambda, s, \text { rat }}
\end{aligned}
$$

where we neglected the nonlinearity of the relation between flux and current.

For the relations between torques and between powers, we can use Fig. 9. The relation between an air-gap torque and the corresponding power can be found by multiplying the torque by the angular speed of the field $\omega_{f}=\omega_{s} / p$.

The loss behavior of power electronic converters is usually unknown. For that reason, we use an estimated relation between the power $P_{e s}$ on the ac side of the secondary inverter and the power $P_{e r}$ on the ac side of the primary inverter as shown in Fig. 10 (exaggerated). The dashed lines in this figure correspond with a constant efficiency $\eta_{e}$. The no-load loss of both inverters together is $P_{d e 0}$. We can find the loss in the power electronic converters by

$$
P_{d e}=\left|P_{e s}-P_{e r}\right| .
$$

\section{Some Characteristic Operation Points}

In this section, we will look at some characteristic operation points for the EVT. For this purpose, we use as an example a traction drive system with a combustion engine with a maximum torque of $850 \mathrm{~N} \cdot \mathrm{m}$ and a maximum power of $160 \mathrm{~kW}$. These are typical values for a Dutch city bus. Because a combustion engine is never used continuously at its maximum torque, we choose the rated input torque of the EVT as $750 \mathrm{~N} \cdot \mathrm{m}$. Furthermore, we choose for this example the same value for the rated outer field torque $\left(n_{\text {rat }}=2\right)$, i.e.,

$$
T_{i \text {,rat }}=T_{o, \text { rat }}=750 \mathrm{~N} \cdot \mathrm{m} \text {. }
$$

A first design was made for a machine having these rated values. This design needs about the same volume as a normal automatic transmission for a city bus. However, the weight is about $50 \%$ more.

The rated frequency for both three-phase windings of the EVT is $50 \mathrm{~Hz}$, and the number of pole pairs is three, i.e.,

$$
\omega_{r, \mathrm{rat}}=\omega_{s, \mathrm{rat}}=2 \pi 50 \mathrm{rad} / \mathrm{s}, \quad p=3 .
$$

For the losses in both machine parts, we use some estimates for normal induction machine losses, i.e.,

$$
\begin{aligned}
P_{\mathrm{Fe}, r, \text { rat }} & =P_{\mathrm{Fe}, s, \text { rat }}=0.5 \mathrm{~kW} \\
P_{\mathrm{Cu}, T, r, \text { rat }} & =P_{\mathrm{Cu}, T, s, \text { rat }}=1.7 \mathrm{~kW} \\
P_{\mathrm{Cu}, \lambda, r, \text { rat }} & =P_{\mathrm{Cu}, \lambda, s, \text { rat }}=0.3 \mathrm{~kW} \\
P_{c i, \text { rat }} & =P_{c o, \text { rat }}=2 \mathrm{~kW} .
\end{aligned}
$$

It should be noted that a good quality magnetic material is used.

Furthermore, there will be no field weakening in the rotor $\left(\lambda_{i}^{\prime}=1\right)$.

When we use soft-switched converters, we can get a high efficiency, i.e.,

$$
P_{d e 0}=300 \mathrm{~W}, \quad \eta_{e}=0.97 .
$$

The considered operating points are given in Table I. In Figs. 11-17, the torque and the power balance are also given for some points. The linewidth in these figures corresponds with the size of the flow.

The aim of this survey is just to get an impression of the distribution of the losses in the system. As mentioned before, we do not have a good validated model of the interrotor saturation yet. This means that the computation of the magnetization currents is not reliable. Furthermore, no extra (mechanical, ventilation) losses have been taken into account.

The first row (i.e., a) in Table I corresponds with standstill (Fig. 11). Because the direct contribution of the input torque $\left(T_{m 1}=270 \mathrm{~N} \cdot \mathrm{m}\right)$ to the output torque $\left(T_{m 2}=2250 \mathrm{~N} \cdot \mathrm{m}\right)$ is small, the stator air-gap torque and the corresponding copper losses are very high. Because there is no field weakening, the losses in the squirrel-cage windings are equal (and relatively high).

Rows b- $\mathrm{d}$ in Table I are for the case of an acceleration in which the inner and outer air-gap torques are equal to their rated values (Fig. 12). There is no large change in the copper losses, and the iron losses are still low.

Row d in Table I (Fig. 13) is for the case of an acceleration with maximum electric power (9). The losses are about their rated values. Furthermore, it can be seen that the torque $T_{r s}$ is reversed (from row c).

Rows d-g in Table I are for the case of an acceleration with high power. In this case, the stator field is weakened $\left(\lambda_{o}^{\prime}<1\right.$; Fig. 14).

Row $\mathrm{f}$ is for the case of direct drive (Fig. 15). In this case, it is very clear that the outer squirrel-cage winding contributes to the output torque while the stator torque is very small and even counteracts the input torque (the stator works as a generator). The contribution of the outer squirrel-cage winding results in a 
TABLE I

SOME CHARACTERISTIC Operating POINTS

\begin{tabular}{|c|c|c|c|c|c|c|c|c|c|c|c|c|c|c|c|c|c|c|c|c|}
\hline & $\begin{array}{c}\omega_{m 1} \\
n_{1} \\
\mathrm{rpm}\end{array}$ & $T_{m 1}$ & $\mathrm{~kW}$ & $\begin{array}{c}\omega_{r} \\
f_{r} \\
\mathrm{~Hz}\end{array}$ & $P_{C u, r}$ & $P_{F e, r}$ & $P_{e r}$ & $P_{d e}$ & $P_{e s}$ & $\begin{array}{c}\omega_{s} \\
f_{s} \\
\mathrm{~Hz}\end{array}$ & $\lambda_{o}^{\prime}$ & $P_{C u, s}$ & $P_{F e, s}$ & $T_{r s}$ & $P_{c i}$ & $P_{c o}$ & $\begin{array}{c}\omega_{m 2} \\
n_{2} \\
\mathrm{rpm}\end{array}$ & $T_{m 2}$ & $P_{m 2}$ & $\eta$ \\
\hline & 800 & & 7 & & 05 & 0.3 & 20.8 & 0.7 & חمת & 2 & 1.0 & 121 & 0.0 & 855 & 4.5 & 4.5 & 0 & 250 & 0 & 0 \\
\hline b & 800 & 9 & 0.9 & -29 & 1.0 & 0.2 & 28.2 & 0.9 & 27.3 & 11 & 1.0 & 5.4 & 0.0 & 261 & 2.0 & 2.0 & 200 & 1500 & 31.4 & 0.77 \\
\hline c & 1300 & 766 & 4.3 & -34 & 2.1 & 0.2 & 51.8 & 1.6 & 50.2 & 31 & 1.0 & 1.9 & 0.2 & -16 & 2.0 & 2.0 & 600 & 1500 & 94.3 & 0.90 \\
\hline $\mathrm{d}$ & 1900 & 767 & 52.6 & -49 & 2.1 & 0.5 & 75.7 & 2.3 & 73.4 & 46 & 1.0 & 1.9 & 0.4 & -17 & 2.0 & 2.0 & 900 & 1500 & 141.4 & 002 \\
\hline e & 1900 & 71 & 3.3 & -24 & 2.1 & 0.1 & 36.3 & 1.1 & 35.2 & 71 & & 0.5 & 0.5 & -99 & 1.6 & 0.8 & 1400 & 1000 & 146.6 & 0.90 \\
\hline $\mathrm{f}$ & 1900 & 73 & 3.8 & 1 & 2.1 & 0.0 & -3.8 & 0.3 & -4.1 & 96 & 0.5 & 0.1 & 0.4 & -173 & 1.3 & 0.3 & 1900 & 750 & 149.2 & 0.97 \\
\hline $\mathrm{g}$ & 1900 & 79 & 154.9 & 16 & 2.1 & 01 & -28.2 & 0.9 & -29.1 & 111 & 04 & 04 & 0.4 & -218 & 1.1 & 0.2 & 2200 & 650 & 149.8 & 0.97 \\
\hline $\mathrm{h}$ & 1200 & 397 & 49.9 & 50 & 0.8 & 0.2 & -26.2 & 0.9 & -27.1 & 90 & 0.5 & 0.5 & 0.4 & -197 & 0.1 & 0.0 & 1800 & 250 & 47.1 & 0.95 \\
\hline & 800 & 72 & 1.2 & -51 & 0.7 & 0.5 & 38.4 & 1.2 & 37.2 & -11 & 1.0 & 6.0 & 0.0 & -872 & 0.9 & 0.9 & -200 & -1000 & 20.9 & 0.67 \\
\hline
\end{tabular}
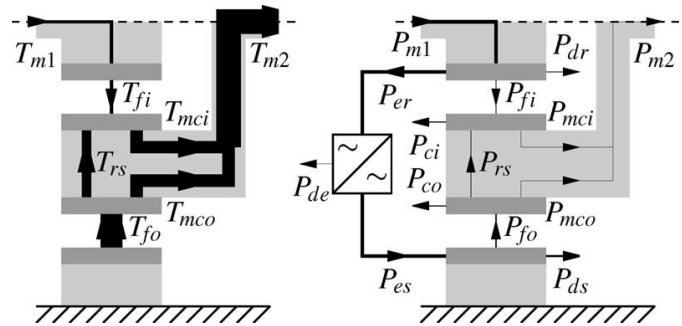

Fig. 11. Standstill mode with high output torque (row a in Table I).
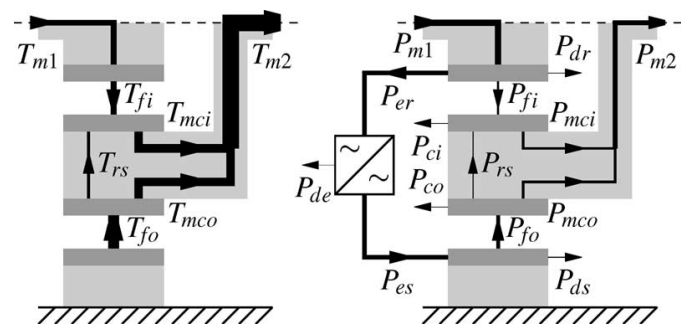

Fig. 12. Normal acceleration mode for very low speed (row b in Table I).

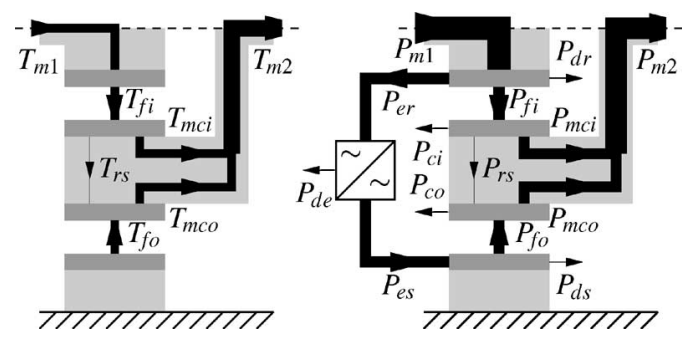

Fig. 13. Acceleration mode with maximum electric power (row d in Table I).

lower loading of the inner squirrel-cage winding and thus lower losses. Furthermore, we can see that the electric power flow is reversed.

These phenomena are much clearer with the further acceleration with high power in overdrive mode (row g; Fig. 16).

An important advantage of the EVT is the possibility of a relatively strong overdrive in case of partial load. This is shown in row h. In this case, the efficiency of the EVT is smaller, but the combustion engine can be operated in a more efficient operating point, which results in a reduction of the fuel consumption [5].

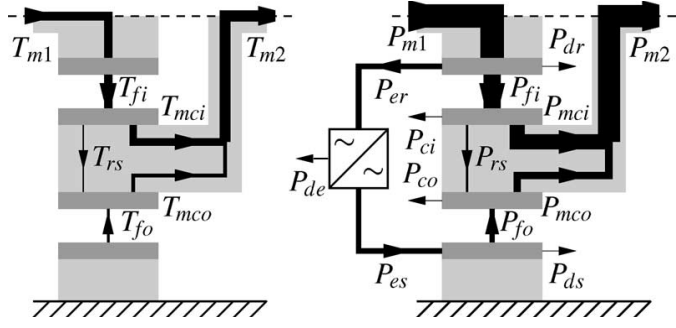

Fig. 14. Acceleration mode with high power (row e in Table I).

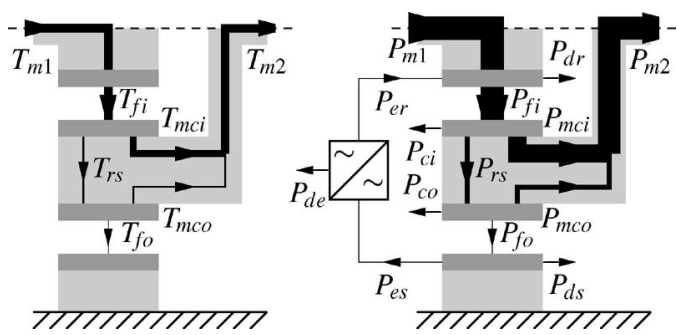

Fig. 15. Direct-drive mode (row $\mathrm{f}$ in Table I).

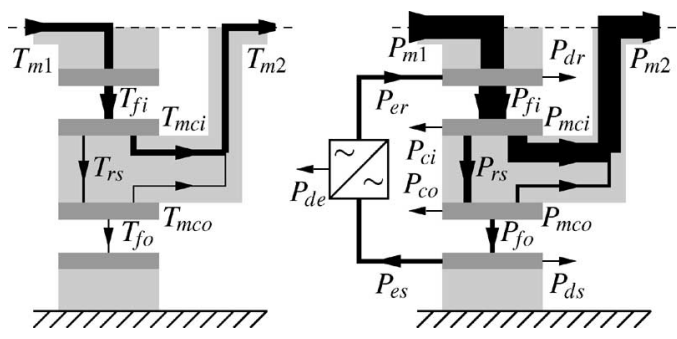

Fig. 16. Overdrive mode (row $\mathrm{g}$ in Table I).

If the output speed is reversed (row i; Fig. 17), we get very high copper losses in the stator because the stator torque has to oppose the rotor torque.

We may conclude from Table I that the efficiency of the EVT is very good in a large operating area. For a large part, this is caused by the fact that the contribution of the outer air-gap torque to the secondary shaft torque is small in a large operating area. This results in low stator copper losses and low stator iron losses (because we may reduce the stator flux). Furthermore, because the frequency in the (primary) rotor is relatively low in a large operating area, the iron losses in the rotor are also low. 


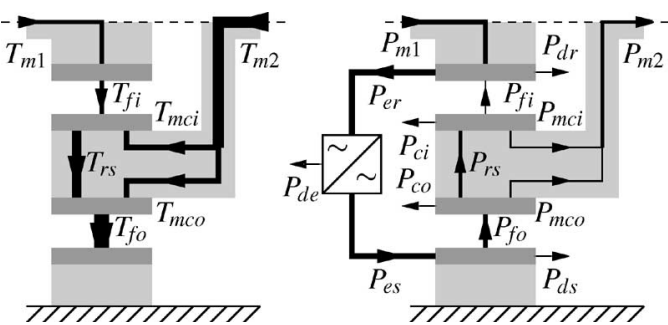

Fig. 17. Reverse mode (row i in Table I).

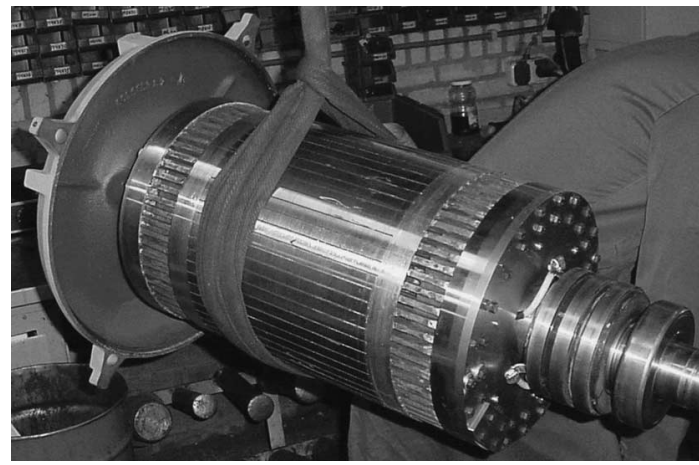

Fig. 18. Rotor/interrotor set.

Only the copper losses in the rotor and in the inner squirrel-cage winding are significant.

\section{PRoof of ConcePt}

For the proof of concept, a machine was made using a standard slipring armature of an induction machine and a standard induction machine stator. Only the interrotor was purpose built (see Fig. 18).

For the experiments, the EVT is driven by a dc motor and loaded by a dc generator (see Fig. 19). The dc bus between the two inverters is connected to the electricity grid by means of a diode bridge rectifier. Hence, the dc voltage is always above approximately $520 \mathrm{~V}$. The primary inverter has a brake insulated gate bipolar transistor (IGBT) with resistor, which limits the dc voltage to about $680 \mathrm{~V}$.

The frequencies of both inverters have always been adjusted together, so that the input rotational speed is kept constant. The torque of the generator has been adjusted in such a way that the dc voltage is between 600 and $650 \mathrm{~V}$. Hence, neither the diode bridge nor the brake resistor is active, so that there is no external power flow to or from the dc bus.

The system has operated in all important operation areas (reverse, underdrive, and overdrive). Some results are shown in Fig. 20. However, because the machine made for the proof of concept had some serious mechanical imperfections, no efficiency measurements could be carried out.

\section{CONCLUSION}

The EVT is an electromechanical system that can be useful as a continuously variable transmission in a motor vehicle, in which it also works as a starter motor and a generator. It

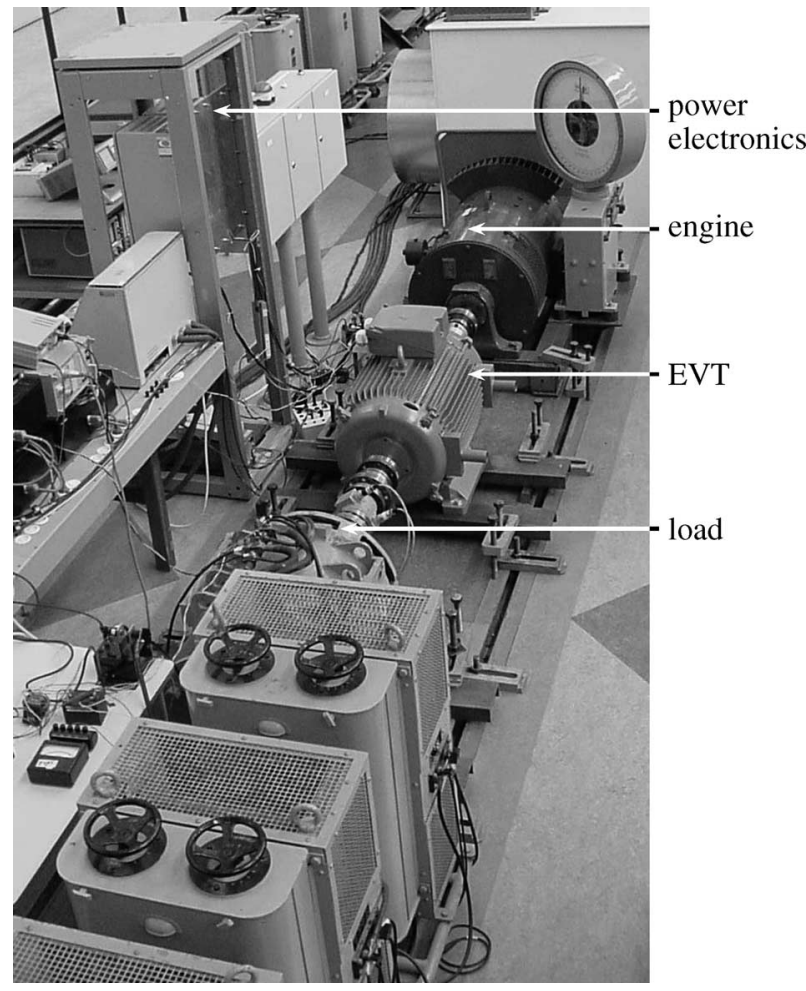

Fig. 19. Experimental setup.

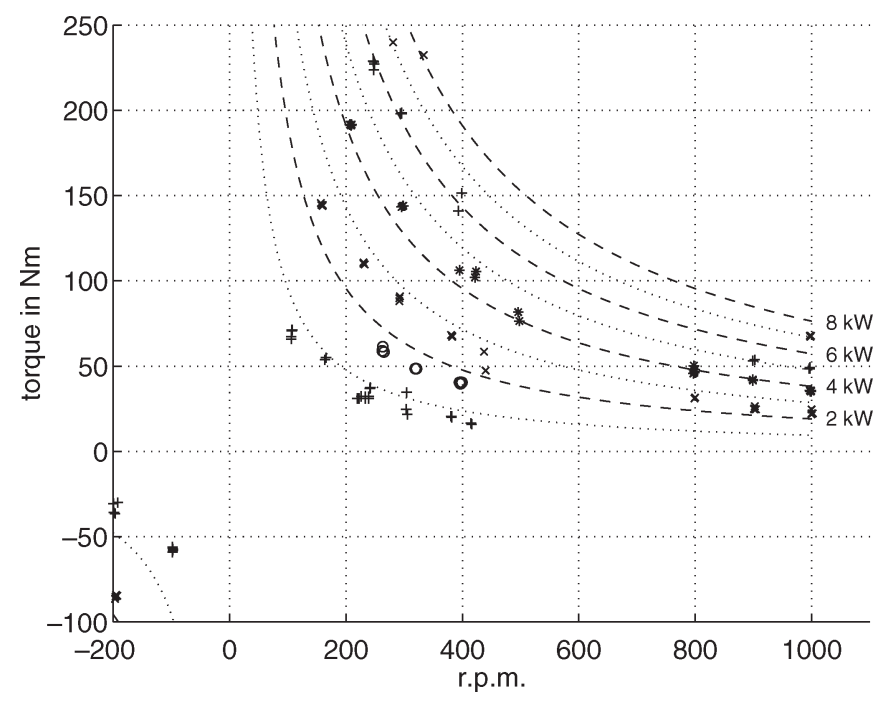

Fig. 20. Output torque-speed characteristics for $700-r / m i n$ input speed.

allows the engine to work with better efficiency, which can increase the fuel efficiency. Furthermore, it may be used in other applications, such as hybrid vehicles.

It was shown that the rating of the system components can be considerably smaller than the main power flow.

The EVT differs from similar designs because of the thin interrotor. This reduces the mass and gives rise to an additional synchronous torque between rotor and stator.

The EVT has a very high efficiency in an important operation area. 


\section{REFERENCES}

[1] G. Altenbernd, H. Schaefer, and L. Waehner, "Present stage of development of the vector controller crankshaft starter-generator for motor vehicle," in Proc. SPEEDAM, Jun. 13-16, 2000, pp. A4-15-A4-20.

[2] S. Chen, B. Lequesne, R. R. Henry, Y. Xue, and J. J. Ronning, "Design and testing of a belt-driven induction starter-generator," IEEE Trans. Power Electron., vol. 38, no. 6, pp. 1525-1533, Nov./Dec. 2002.

[3] L. Loewenstein and G. Henneberger, "Development of a transverse flux reluctance machine for a crankshaft starter-alternator," in Proc. SPEEDAM, Jun. 13-16, 2000, pp. BB1-19-BB1-22.

[4] P. J. McCleer, J. M. Miller, A. R. Gale, M. W. Degner, and F. Leonardi, "Nonlinear model and momentary performance capability of a cage rotor inductin machine used as an automotive combined starter-Alternator," IEEE Trans. Ind. Appl., vol. 37, no. 3, pp. 840-846, May/Jun. 2001.

[5] M. J. Hoeijmakers and M. Rondel, "The electrical variable transmission in a city bus," in Proc. 35th IEEE Power Electron. Specialist Conf., Aachen, Germany, Jun. 2004, pp. 2773-2778.

[6] K. Jonasson, P. Strandh, and M. Alakuela, "Comparative study of generic hybrid topologies," in Proc. 18th Electric Veh. Symp., Berlin, Germany, 2001, CD-ROM.

[7] C. C. Chan, "The state of the art of electric and hybrid vehicles," Proc. IEEE, vol. 90, no. 2, pp. 247-275, Feb. 2002.

[8] J. Miller, "Power electronics in hybrid electric vehicle applications," in Proc. 18th Annu. IEEE APEC, Feb. 2003, vol. 1, pp. 23-29.

[9] J. Miller, S. Schulz, B. Conlon, M. Duvall, M. Kankam, and N. Nagel, "Adjustable speed drives transportation industry needs: Part IAutomotive," in Proc. 58th IEEE VTC-Fall, Oct. 2003, vol. 5, pp. 3220-3225.

[10] Y. Gao, M. Ehsani, and J. Miller, "Hybrid electric vehicle: Overview and state of the art," in Proc. IEEE ISIE, Jun. 2005, vol. 1, pp. 307-316.

[11] D. Hermance and S. Sasaki, "Hybrid electric vehicles take to the streets," IEEE Spectrum, vol. 35, no. 11, pp. 48-52, Nov. 1998.

[12] S. Sasaki, "Toyota's newly developed hybrid powertrain," in Proc. 10th ISPSD and ICs, Jun. 1998, pp. 17-22.

[13] S. Eriksson and C. Sadarangani, "A four-quadrant hev drive system," in Proc. 56th IEEE VTC - Fall, 2002, vol. 3, pp. 1510-1514.

[14] K. Hefel, "Electric transmission gearing," U.K. Patent 461 306, Jan. 1935.

[15] F. Shibata, "Electric control system of an electric machine arrangement combining electromagnetic coupling with electric rotating machine," U.S. Patent 3 789 281, Jan. 29, 1974.

[16] G. T. Rodenhuis, "Dynamoelectric gear," EP Patent 1154551 A2, Jan. 2000

[17] E. Nordlund, P. Thelin, and C. Sadarangani, "Four-quadrant energy transducer for hybrid electric vehicles," in Proc. 15th ICEM, Brugge, Belgium, Aug. 25-28, 2002, CD-ROM.

[18] F. Magnussen, Y. Chin, J. Soulard, A. Broddefalk, S. Eriksson, and C. Sadarangani, "Iron losses in salient permanent magnet machines at field-weakening operation," in Proc. 39th IEEE-IAS Annu. Meeting, Seattle, WA, Oct. 2004, p. 47.

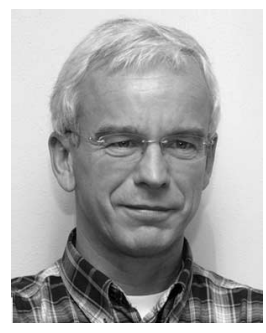

Martin J. Hoeijmakers ( ' $^{\prime} 80-\mathbf{M}^{\prime} 80$ ) was born in Geertruidenberg, The Netherlands, in 1956. He received the M.Sc. and Ph.D. degrees in electrical engineering from Eindhoven University of Technology, Eindhoven, The Netherlands, in 1980 and 1984, respectively.

From 1984 to 1991, he was an Assistant/Associate Professor with Eindhoven University of Technology. Since 1991, he has been an Associate Professor with Delft University of Technology, Delft, The Netherlands. He was a Consultant for the Netherlands Energy Research Foundation and for NedWind Rhenen. From 1989 to 1991, he worked part-time at the Netherlands Energy Research Foundation. Since 1999, he has been a part-time business associate in EMechForce, Delft, The Netherlands, an engineering company that specializes in consulting and implementation services in electromechanics and electrical drive systems. His main research interests are traction drive systems, in particular, the electrical variable transmission.

Dr. Hoeijmakers received the Hidde Nyland Award in 1996 for his contributions to electrical power engineering.

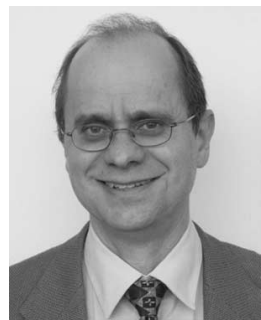

Jan A. Ferreira (M'88-SM'01-F'05) received the B.Sc.Eng., M.Sc.Eng., and Ph.D. degrees from Rand Afrikaans University, Johannesburg, South Africa, in 1981, 1983, and 1988, respectively, all in electrical engineering.

In 1981, he was with the Institute of Power Electronics and Electric Drives, Technical University of Aachen, and worked in industry at ESD (Pty.) Ltd. from 1982 to 1985 . From 1986 to 1997 , he was with the Faculty of Engineering, Rand Afrikaans University, where he held the Carl and Emily Fuchs Chair of power electronics in later years. Since 1998, he has been a Professor with Delft University of Technology, Delft, The Netherlands.

Dr. Ferreira was the Chairman of the South African Section of the IEEE from 1993 to 1994. He is the Founding Chairman of the IEEE Joint Industry Applications Society/Power Electronics Society (IAS/PELS) Benelux chapter. He served as the IEEE TRANSACTIONS ON INDUSTRY APPLICATIONS Review Chairman for the IEEE Industry Applications Society Power Electronic Devices and Components Committee and is an Associate Editor of the IEEE TRANSACTIONS ON POWER ElECTRONICS. He was a member of the IEEE Power Electronics Specialists Conference Adcom and is currently the Treasurer of the IEEE PELS. He served as the Chairman of the CIGRE SC14 National Committee of the Netherlands and was a Member of the Executive Committee of the European Power Electronics Society. 